\title{
Sleep conditions and quality of life among patients with ischemic heart disease after elective percutaneous coronary intervention
}

\author{
Yuko Yasuhara ${ }^{1 \#}$, Haruo Kobayashi ${ }^{2}$, Tetsuya Tanioka' ${ }^{1}$, Eiji Fujikawa ${ }^{3}$, Hiroyuki Fujinaga ${ }^{4}$ \\ Warapon Kongsuwan ${ }^{5}$, Rozzano C. Locsin ${ }^{6}$

\footnotetext{
${ }^{1}$ Department of Nursing, Institute of Health Biosciences, The University of Tokushima Graduate School, Tokushima, Japan;

\#Corresponding Author: yasuhara@medsci.tokushima-u.ac.jp

${ }^{2}$ Faculty of Medical Welfare, Kawasaki University of Medical Welfare, Kurashiki, Japan

${ }^{3}$ Department of Nursing, Tokushima Prefectural Central Hospital, Tokushima, Japan

${ }^{4}$ Department of Cardiovascular Internal Medicine, Tokushima Prefectural Central Hospital, Tokushima, Japan

${ }^{5}$ Department of Medical Nursing, Faculty of Nursing, Prince of Songkla University, Songkhla, Thailand

${ }^{6}$ Christine E. Lynn College of Nursing, Florida Atlantic University, Boca Raton, USA
}

Received 15 January 2013; revised 18 February 2013; accepted 28 February 2013

\begin{abstract}
In Japan, percutaneous coronary intervention (PCI) is a major therapeutic intervention for ischemic heart disease (IHD). Previous studies suggested that an association of the risk of IHD caused by sleep duration was related to factors closely associated with daily activities. However, in Japan, there is no study about this relationship objectively measured using the actigraphy in patients with IHD. Moreover, there is little reported data about sleep condition and early outcomes of patient's Health-Related Quality of Life (QOL) after PCI. This study determines the correlations between sleep conditions and QOL (measured by SF36 version 2) of 25 patients with IHD who underwent elective PCI. Data were collected seven days after $\mathrm{PCl}$ using night-sleep condition. Using Spearman's rank test, the results revealed positive correlation between vitality score and longest sleep duration $(\rho=0.43$, $p=0.031$ ): social functioning (SF) score and duration of night-time sleep $(\rho=0.42, p=0.037)$; total sleep duration $(\rho=0.45, p=0.026)$, and longest sleep duration $(\rho=0.44, p=0.024)$; mental health score and longest sleep duration $(\rho=0.54, p=0.006)$. However, negative correlation was found between physical functioning score and arousal during sleep $(\rho=-0.44, p=$ 0.027 ). Sleep condition was significantly correlated with QOL. In particular, SF score was positively related to night-time sleep. This seems to
\end{abstract}

*Conflict of Interest: None of the authors have any conflict of interest to declare. indicate that SF score might be related to nighttime sleep condition. Moreover, the longest sleep durations were correlated with the mental component summary. The results of the study suggest that not only the length of whole sleep durations leads to better QOL, but also the increase the amount of uninterrupted sleep.

Keywords: Ischemic Heart Disease; Actigraphy; Sleep Condition; Health-Related Quality of Life

\section{INTRODUCTION}

Lifestyle changes such as consuming western-style food, overeating and a lack of exercise have led to an increasing incidence of metabolic syndrome complicated with coronary artery disease in Japan [1,2]. Metabolic syndrome is characterized by excessive fat around the internal organs, leading to abnormal lipid metabolism, impaired glucose tolerance and hypertension [3]. Around 20 million Japanese in their 40s to 70 s already have or were more likely to suffer from metabolic syndrome in 2006 [4], suggesting that more patients will develop is IHD in the future.

PCI is the main therapeutic treatment for IHD. The development of medical technologies such as drugeluting stents has significantly reduced the hospital death rates of patients with acute myocardial infarction [5]. However, IHD is a disease that is linked to recurrent arterial stenosis and coronary artery infarction. Continuous improvements in lifestyle, oral medicines and periodic catheter examinations are essential to prevent IHD recurrence. Many reports indicate that continuous physical activity reduces cardiovascular risk [6,7] and improves 
the person's QOL $[8,9]$.

Comprehensive cardiac rehabilitation (CCR) prevents restenosis and improves QOL [10] which includes patient education delivered by medical teams about dietary changes, lifestyle, and the importance of regular medication, social psychological support and exercise regimens [11]. However, only a few hospitals offer CCR in Japan due to lack of facilities and personnel experts [12]. In addition, patients with IHD who undergo elective PCI at present usually do not receive CCR. However, patients must self-regulate their life rhythms such as activities and rest, which will benefit cardiac functioning immediately after receiving medical treatments and improved lifestyle habits. Such patients have often reported feeling that repeated PCI is undesirable but necessary and that they feel physically unhealthy after treatment [13].

Some investigators have identified an association between increased risk of IHD and sleep duration [14-17], a factor that is closely associated with daily activities. Various studies have examined the relationship between sleep duration and cardiovascular mortality. Previous studies have indicated relationships among sleep quality, psycho-physiological symptoms and QOL by inventory [18]. Redeker et al. [19-21] suggested that interventions to improve sleep during hospitalization and post-hospitalization were important for the recovery of patients under cardiac care. Sleep contributes to both physical functioning and emotional wellbeing from 4 to 8 weeks after cardiac surgery operation in patients in the USA. Other related studies $[22,23]$ after cardiac surgery operation has generated similar findings. However, the quality of sleep among Japanese patients with IHD has never been objectively surveyed using actigraphy.

There were previous studies about patients with percutaneous transluminal coronary angioplasty (PTCA), for example, Edéll-Gustafsson and Hetta [16] who reported that sleep quality was related to anxiety and depression, selected psycho-physiological sleep-disturbing symptoms, daytime dysfunctions according to poor sleep, and QOL at 1 year after PTCA. Hatano et al. [24] reported that QOL scores are significantly lower among patients with IHD who were hospitalized for the first time and those who were re-hospitalized within three months compared with a control group. Similarly, Matsuoka et al. [25] assessed factors related to QOL among patients with IHD after coronary intervention; they suggested that the QOL of patients with IHD is related to the presence or absence of coronary restenosis and an irregular heartbeat, coronary disease severity and social support as well as several other factors. Although QOL was evaluated using the SF-36, the subscale of general health perception and social functioning were significantly higher among such patients without arrhythmias after coronary invention. Furthermore, as mental health is related to family and organizational support, their findings suggested a relationship between QOL and IHD. A relationship between the objective sleep index of Japanese patients with IHD and their QOL has not been clarified, although a range of factors are known to influence QOL.

To continuously treat patients with IHD and improve their QOL, sleep and wake rhythms must be established based on their sleep patterns. Understanding the association between sleep and QOL during this period could enable the provision of information to patients with IHD about the importance of maintaining fine-quality sleeping habits as well as suitable daily activities.

Sleep disorders [26] are commonly under-diagnosed and comprise a significant source of concern in the geriatric population; however, treating insomnia in patients with IHD can improve overall health. That is, better sleep could improve lifestyle rhythms and thus the QOL of the elderly and of patients with IHD.

\section{PURPOSE}

The aim of this study was to analyse the relationship between sleep conditions and quality of life among patients with ischemic heart disease after elective percutaneous coronary intervention

\section{METHODS}

\subsection{Subjects and Study Location}

The subjects of the study met the following inclusion criteria: 1) no undergoing CCR; 2) the ability to complete a questionnaire; 3) no history of heart failure or life-threatening arrhythmia before PCI; 4) free of chronic psychiatric diseases requiring psychotropic medication, and/or having sleep disorders; and 5) underwent elective PCI of initial therapy or who underwent two or more retreatment by PCI.

This study was conducted at a general public hospital located in Shikoku, Japan. Twenty-five patients with IHD treated with elective PCI were selected and data collected between August 2009 and August 2011were analyzed.

Of the total, there are 25 patients (male, $\mathrm{n}=14$ (56.0\%); Female, $\mathrm{n}=11(44.0 \%)$; average age, $65.1 \pm 11.4$ years, range 47 - 88 years; multiple PCI, $n=19(76.0 \%))$.

\subsection{Data Collection Methods}

\subsubsection{Sleep Condition Measured by Actigraphy}

Actigraphy is a simple procedure that is used to assess sleep-wake cycles. The patients wore actigraph accelerometers (Ambulatory Monitoring, Inc. Ardsley, NY, USA) on the non-dominant wrist for 7 days (except when bathing), starting from 1 to 2 days before discharge and 6 
days after discharge from the hospital. Day of discharge was excluded in the duration count. Actigraph data using the sleep/awake formula of Cole and others closely correlate with polysomnography, with reliability coefficients ranging from 0.89 to 0.98 for normal sleep [2729].

\subsubsection{Health-Related Quality of Life (QOL)}

The QOL survey was administered on the seventh day after discharge using the health-related scale of SF36 ver2 TM: Medical Outcomes study 36-Item Short-Form Health Survey, Standard, Japanese version; SF36 ver2. This simple generic measure minimally burdened the subjects. It consists of the following eight subscales (2 10 items): physical functioning (PF; 10 items), role physical (RP; 4 items), bodily pain (BP; 2 items), social functioning (SF; 2 items), general health perceptions (GH; 5 items), vitality (VT; 4 items), role emotional (RE; 3 items) and mental health (MH; 5 items). Each item comprises five scores on the Likert scale. The maximum total score for each item ranges from 0 to 100 . Higher total scores are considered to represent a higher QOL. The Cronbach's alpha coefficient of the eight subscales was $0.77-0.93$ [30-32].

\subsection{Data Analysis}

In this study, the researchers analyzed the data collected on the seventh day after discharge from the hospital. The data revealed that the number of times of arousal during sleep and rest hours in the daytime was more decreased than immediately after being discharged from the hospital.

Actigraphic data were imported from the external interface using an ACT2000/ACT Millennium, displayed and analyzed using Action W-2 software (Ambulatory Monitoring) based on a standardized sleep scoring algorithm [29]. The eight subscales of SF36 ver2 were scored by specialized scoring software (Excel version). Correlations between each sleep item such as sleep onset and offset times (hh:min:ss), duration from onset to offset time ( $\mathrm{min}$ ), mean activity (counts/min), duration of being totally awake (minutes), total sleep duration excluding any amount of time being awake (min), and \% sleep, sleep latency $(\mathrm{min})$ and the activity index (epoch with $>0$ activity score; \%) and SF36 ver2 were analyzed by Spearman's rank-order test.

All data were analysed using IBM SPSS ver. 19.0. The level of significance was set at $\mathrm{p}<0.05$.

\subsection{Ethical Considerations}

The study was approved by the Ethics Committee of Tokushima Prefectural Central Hospital (No 09-07) and the Tokushima University Hospital Ethics Board (No.
1257). The following issues were carefully explained to the patients orally and in writing: the purpose and content of the study; the voluntary nature of participation and that refusal to participate would not cause any disadvantages; the freedom of approving or disapproving the findings to be used in presentation of the research; and the rights of anonymity and secure confidentiality. The patients included in the study provided written informed consent to participate.

\section{RESULTS}

Table 1 shows correlations between night-time sleep and QOL. Positive correlations were found between VT score and longest sleep duration $(\rho=0.43, \mathrm{p}=0.031)$, between SF score and night-time duration $(\rho=0.42, \mathrm{p}=$ $0.037)$, between total $(\rho=0.45, \mathrm{p}=0.026)$, and longest $(\rho=0.44, \mathrm{p}=0.026)$ sleep duration, and between $\mathrm{MH}$ score and longest sleep duration $(\rho=0.54, \mathrm{p}=0.006)$. On the other hand, the negative correlation between PF score and arousal during sleep was obtained $(\rho=-0.44$, $\mathrm{p}=0.027)$.

\section{DISCUSSION}

This study clarified the relationship between sleep conditions and the QOL at 7 days after discharge from hospital (when patients returned home to assume one's life activities as it was before hospitalization (premorbid state).

Arousal during sleep and PF score was negative and correlated significantly, suggesting that the incidence of arousal during sleep decreased, accompanied by an increase in daytime physical activity. Yoshimura et al. [33] found that night-time urinary frequency was one of the reasons for arousal during sleep, and was the most closely associated with the three Medical Outcome Study Short Form-8 (SF-8) domains of PF, RP, and SF score. Arousal during sleep in the present study was not only caused by having to wake up to cause urination, but it also suggested that interrupting sleep might decrease this QOL score. Promoting uninterrupted sleep might lengthen sleep duration at night. Furthermore, longest sleep duration also positively correlated with VT, SF, and $\mathrm{MH}$ score. These data suggested that longer sleep duration leads to an improvement in the degree of satisfaction with sleep felt by patients which might increase mental QOL sub scores such as VT score, or SF score and MH score in the mental component summary (MCS). The eight subscales of the SF36 ver2 can use the scores of the physical component summary (PCS) and MCS. However, these scores of the Japanese version pointed out problems remaining in the SF36 ver2 when sample sizes are small and people with diseases are monitored [34].

To avoid the limitation, each eight subscale scores of 
Table 1. Correlations between data from the actigraph in the night-time and QOL.

\begin{tabular}{|c|c|c|c|c|c|c|c|c|c|c|c|}
\hline \multirow[b]{2}{*}{$\begin{array}{l}8 \text { subscale of } \\
\text { SF36 ver } 2\end{array}$} & \multicolumn{11}{|c|}{ Item of Actigraphy } \\
\hline & Onset-time & Offset-time & duration & $\begin{array}{c}\text { Mean } \\
\text { Activity }\end{array}$ & $\begin{array}{c}\text { Total wake } \\
\text { duration }\end{array}$ & $\begin{array}{c}\text { Total sleep } \\
\text { duration }\end{array}$ & $\begin{array}{l}\text { Percent } \\
\text { sleep }\end{array}$ & $\begin{array}{l}\text { Sleep } \\
\text { latency }\end{array}$ & $\begin{array}{c}\text { Arousal } \\
\text { during } \\
\text { sleep }\end{array}$ & $\begin{array}{l}\text { Logest } \\
\text { sleep } \\
\text { duration }\end{array}$ & $\begin{array}{c}\text { Activity } \\
\text { index }\end{array}$ \\
\hline $\begin{array}{l}\text { PF (Physical } \\
\text { Functioning) }\end{array}$ & 0.16 & -0.28 & -0.30 & -0.35 & -0.35 & -0.20 & 0.28 & 0.32 & $-0.44^{*}$ & 0.21 & -0.33 \\
\hline $\begin{array}{l}\text { RP (Role } \\
\text { Physical) }\end{array}$ & -0.04 & -0.07 & -0.01 & 0.17 & 0.18 & -0.05 & -0.30 & 0.33 & 0.17 & 0.30 & 0.25 \\
\hline $\begin{array}{l}\text { BP (Bodily } \\
\text { Pain) }\end{array}$ & 0.27 & -0.13 & -0.21 & 0.01 & 0.08 & -0.22 & -0.13 & 0.23 & 0.20 & 0.20 & -0.05 \\
\hline $\begin{array}{l}\text { GH (General } \\
\text { Health } \\
\text { Perceptions) }\end{array}$ & -0.20 & 0.01 & 0.30 & 0.30 & 0.33 & 0.25 & -0.28 & 0.14 & 0.26 & 0.27 & 0.18 \\
\hline VT (Vitality) & 0.02 & 0.06 & 0.21 & 0.27 & 0.29 & 0.21 & -0.30 & 0.22 & 0.30 & $0.43^{*}$ & 0.20 \\
\hline $\begin{array}{l}\text { SF (Social } \\
\text { Functioning) }\end{array}$ & -0.16 & 0.20 & $0.42^{*}$ & 0.03 & 0.15 & $0.45^{*}$ & 0.05 & -0.09 & 0.08 & $0.44^{*}$ & 0.16 \\
\hline $\begin{array}{c}\text { RE (Role } \\
\text { Emotional) }\end{array}$ & 0.14 & -0.07 & -0.04 & -0.04 & -0.03 & -0.05 & -0.01 & 0.22 & 0.03 & 0.19 & 0.27 \\
\hline $\begin{array}{c}\text { MH (Mental } \\
\text { Health) }\end{array}$ & -0.09 & 0.04 & 0.20 & 0.08 & 0.18 & 0.17 & -0.11 & 0.04 & 0.08 & $0.54^{* *}$ & 0.05 \\
\hline
\end{tabular}

"Specarman's ran-order test, $\rho$ (two-sided), ${ }^{*} \mathrm{p}<0.05,{ }^{* *} \mathrm{p}<0.01$.

SF36 ver. 2 was used in this study. Although, MCS was not analyzed in this study, it does show that uninterrupted sleep might affect the mental health component summary and thus the amount of uninterrupted sleep is also important for mental health in Japanese patients with IHD.

Takenaka et al. [35] reported that administering a short-acting sleeping agent to patients with insomnia caused a significant improvement in the Pittsburgh Sleep Quality Index (PSQI) scores and in the MCS in SF36. The longest sleeping durations by actigraphy have not been sufficient. A key topic for future studies might be to determine care methods that aim to lengthen sleep duration.

SF score in SF36 ver2, duration of nighttime, total sleep duration and longest sleep duration were positively correlated. SF score evaluates the degree of emotional or physical problems; lower social function could become a barrier to normal social activities. Among individuals aged $\geq 65$ years, $46 \%$ spend most of their time alone except when asleep, and $78 \%$ live alone [36]. Thus, the number of social interactions tends to decrease among elderly individuals. Previous studies [7,8,37] have described a relationship between CCR and QOL. The benefits of CCR are the prevention of coronary artery restenosis, and also increase the possibility of interactions with others person. However, since the patients of this research have not participated in CCR, if they spend daytime hours alone indoors; they might also have poor sleep conditions during the night-time. Conversely, improving the sleep conditions of patients after elective PCI might help to improve social interactions with others.
Patients with IHD can develop anxiety due to coronary artery restenosis $[13,38]$. Physical activity in the ADL is limited in such patients. This tendency might be more obvious in patients who have not undergone CCR. Therefore, daytime activities should be maintained at levels that are sufficient to avoid poor sleep quality in patients who have not received CCR after PCI. In that sense, CCR might be important for patients with IHD. Hence, information should be provided about CCR, and ADL should be promoted so that longest sleep duration becomes longer.

\section{LIMITATIONS}

This study was limited by the small number of subjects and the inability to investigate how sleep and QOL correspond to age and sex. Sleep quality should be determined by analysing factors such as rapid eye movement (REM) and non-REM sleep. Nevertheless, the present study clarified a relationship between sleep and QOL for the first time in Japanese patients with IHD who had undergone a first PCI. The results suggest that patients with IHD should be provided with information concerning sleep. Future studies should focus on a continuous evaluation of the QOL of patients after elective PCI. Future challenges will be to determine how to improve sleep and promote QOL by clarifying which factors influence sleep.

\section{CONCLUSION}

Sleep condition significantly correlated with QOL. In particular, SF score was positively related to night-time 
sleep items (total sleep duration, and longest sleep duration). SF score might be related to night-time sleep condition. Moreover, the longest sleep durations were related to the mental component summary. Therefore, it was suggested that not only the length of whole sleeping durations but to increase the amount of uninterrupted sleep leads better patients' mental QOL.

\section{IMPLICATION FOR NURSING}

Wrist actigraphy was validated with concurrent polysomnography as a reliable tool with which to objectively measure several standard sleep parameters, including ADL. These data can be used to help patients with IHD anticipate changes in sleep patterns during recovery. Actigraphy was a useful device for measuring of sleep conditions to improve sleep during hospitalization and enhance post-discharge recovery. Longest sleep duration should be improved for patients in the clinical nursing care.

\section{ACKNOWLEDGEMENTS}

We thank all those who co-operated with this survey. This study was supported by the Kawasaki University of Medical Welfare Scientific Research Fund 2011 (Principal investigator, Haruo Kobayashi).

\section{REFERENCES}

[1] Shiwaku, K., Hashimoto, M., Nogi, A., Kitajima, K. and Yamasaki, M. (2004) Traditional Japanese dietary basics: A solution for modern health issues? Lancet, 363, 17371738 .

[2] Mochizuki, K., Misaki, Y., Miyauchi, R., Takabe, S., Shimada, M., Kuriki, K., Ichikawa, Y. and Goda, T. (2012) Higher rate of eating is associated with higher circulating interluekin- $1 \beta$ concentrations in Japanese men not being treated for metabolic diseases. Nutrition, 28, 978-983. doi:10.1016/j.nut.2011.12.001

[3] Oka, R., Kobayashi, J., Inazu, A., Yagi, K., Miyamoto, S., Sakurai, M., Nakamura, K., Miura, K., Nakagawa, H. and Yamagishi, M. (2010) Contribution of visceral adiposity and insulin resistance to metabolic risk factors in Japanese men. Metabolism, 59, 748-754.

[4] Ministry of Health, Labour and Welfare (2012) The outline of health and a nutrition survey result in Japan, 2004. http://www.mhlw.go.jp/houdou/2006/05/h0508-1.html

[5] Hirakawa, Y., Masuda, Y., Kuzuya, M., Iguchi, M., Kimata, T. and Uemura, K. (2007) Impact of gender on inhospital mortality of patients with acute myocardial infarction undergoing Percutaneous Coronary Intervention: An evaluation of the TAMIS-II data. International Medicine, 46, 363-366. doi:10.2169/internalmedicine.46.6137

[6] Witt, B.J., Jacobsen, S.J., Weston, S.A., Killian, J.M., Meverden, R.A., Allison, T.G., Reeder, G.S. and Roger, V.L. (2004) Cardiac rehabilitation after myocardial infaction in the community. Journal of the American College of Cardiology, 44, 988-996. doi:10.1016/j.jacc.2004.05.062

[7] Ornishi, D., Scherwitz, L.W., Billings, J.H., Brown, S.E., Gould, K.L., Merritt, T.A., Sparler, S., Armstrong, W.T., Ports, T.A., Kirkeeide, R.L., Hogeboom, C. and Brand, R.J. (1998) Intensive lifestyle changes for reversal of coronary heart disease. Journal of the American Medical Association, 280, 2001-2007. doi:10.1001/jama.280.23.2001

[8] Jegier, A., Jegier, A., Szmigielska, K., Bilinska, M., Brodowski, L., Galaszek, M., Mrozek, P., Olszewska, B., Piotrowski, W., Przywarska, I., Rybicki, J. and Zielinska, D. (2009) Health-related Quality of life patients with coronary heart disease after residential vs ambulatory cardiac rehabilitation. Circulation Journal, 73, 476-483. doi:10.1253/circj.CJ-08-0407

[9] Choo, J., Burke, L.E. and Hong, K.P. (2007) Improved quality of life with cardiac rehabilitation for post-myocardial infarction patients in Korea. European Journal of cardiovascular Nursing, 6, 166-171. doi:10.1016/j.ejcnurse.2006.07.004

[10] Oldidge, N., Guyatt, G., Jones, N., Crowe, J., Singer, J., Feeny, D., McKelvie, R., Runions, J., Streiner, D. and Torrance, G. (1991) Effects on QOL of life with comprehensive rehabilitation after acute myocardial infarction. The American Journal of Cardiology, 67, 1084-1089. doi:10.1016/0002-9149(91)90870-Q

[11] Ishikawa, K., Ueshima, H., Ogawa, H., et al. (2006) Diagnosis and treatment guideline of the cardiovascular disease (2004-2005 year combination studies squad report). A guideline on the second prevention of myocardial infarction (A 2006 revised edition). Ministry of Health, Labour and Welfare, Tokyo, 1-52.

[12] Gotho, Y., Saitho, M., Iwasaka, S., et al. (2006) Actual situation of the acute myocardial infarction convalescence rehabilitation in Japan. Heart Rehabilitation, 11, 36-40.

[13] Yasuhara, Y., Harano, K., Fujikawa, E., Fuginaga, H., Tanioka, T., Kobayashi, H., Pfaff, G. and Suragarn, U. (2011) Effectiveness of the integration of different types of quantitative and qualitative assessment indicators for the patients with ischemic heart disease who underwent percutaneous coronary intervention (PCI). Proceeding of the 7th International Conference on Natural Language Processing and Knowledge Engineering, Tokushima, 17-19 November 2008, 454-458.

[14] Kripke, D.F., Grfinkle, L., Wingard, D.L., Klauber, M.R. and Marler, M.R. (2002) Mortality associated with sleep duration and insomnia. Arch Gen Psychiatry, 59, 131-136. doi:10.1001/archpsyc.59.2.131

[15] Ikehara, S., Iso, H., Date, C., Kikuchi, S., Watanabe, Y., Wada, Y., Inaba, Y. and Tamakoshi, A. and JACC Study Group (2009) Association of sleep duration with mortality from cardiovascular disease and other causes for Japanese men and women: The JACC study. Sleep, 32, $295-$ 301.

[16] Suzuki, K. (2007) Health conditions and mortality in Japan Collaborative Chort study for evaluation of cancer (JACC). Asian Pacific Journal of Cancer Prevention, 8, 25-33. 
[17] Sabanayagam, C. and Shankar, A. (2010) Sleep duration and cardiovascular disease: Results from the national health interview survey. Sleep, 33, 1037-1042.

[18] Edell-Gustafsson, U.M. and Hetta, J.E. (2001) Fragmented sleep and tiredness in males and females one year after percutaneous transluminal coronary angioplasty (PTCA). Journal of Advanced Nursing, 34, 203-211. doi:10.1046/j.1365-2648.2001.01746.x

[19] Redeker, N.S., Mason, D.J., Wykpisz, E. and Glica, B. (1996) Sleep pattern in women after coronary artery bypass surgery. Applied Nursing Research, 9, 115-122. doi:10.1016/S0897-1897(96)80206-0

[20] Redeker, N.S., Tamburri, L. and Howland, C.L. (1998) Prehospital correlates of sleep in patients hospitalized with cardiac disease. Research in Nursing \& Health, 21, 27-37.

[21] Redeker, N.S., Ruggiero, J.S. and Hedges, C. (2004) Sleep is related to physical function and emotional wellbeing after cardiac surgery. Nursing Research, 53, 154162. doi:10.1097/00006199-200405000-00002

[22] Simpson, T. and Lee, E.R. (1996) Individual factors that influence sleep after cardiac surgery. American Journal of Critical Care, 5, 182-189.

[23] Hedner, J., Caidahl, K., Sjöland, H., Karlsson, T. and Herlitz, J. (2002) Sleep habits and their association with mortality during 5-year follow-up after coronary artery bypass surgery. Acta Cardiologica, 57, 341-348. doi:10.2143/AC.57.5.2005450

[24] Hatano, H., Takeshita, T. and Arita, M. (2007) Factors related to the changes in quality of life over time in patients with ischemic heart disease. Journal of the Wakayama Medical Society, 58, 126-132.

[25] Matsuoka, M., Kawakami, C., Chisaki, A., Shinohara, J., Nagaie, T., Akashi, C. and Hara, Y. (2006) Factors related to QOL of patients with ischemic heart disease after coronary inventions. The Journal of Japanese Association of Cardiovascular Nursing, 1, 24-33.

[26] Matsuoka, M., Kawakami, C., Chisaki, A., Shinohara, J., Nagaie, T., Akashi, C. and Hara, Y. (2006) Factors related to QOL of patients with ischemic heart disease after coronary inventions. The Journal of Japanese Association of Cardiovascular Nursing, 1, 24-33.

[27] Ancoli-Israel, S., Cole, R., Alessi, C., Chambers, M., Moorcroft, W. and Pollak, C.P. (2003) The role of actigraphy in the study of sleep and circadian rhythms. Sleep, 26, 342-392.

[28] Shinkoda, H., Matumoto, K., Hamasaki, J., Seo, Y.J.,
Park, Y.M. and Park, K.P. (1998) Evaluation of human activities and sleep-wake identification using wrist actigraphy. Psychiatry and Clinical Neurosciences, 52, 157 159. doi:10.1111/j.1440-1819.1998.tb01004.x

[29] Cole, R.J., Kripke, D.F., Gruen, W., Mullaney, D.J. and Gillin, J.C. (1992) Automatic sleep/wake identification from wrist activity. Sleep, 15, 461-469.

[30] Fukuhara, S., Ware, J.E., Konishi, M., Wada, S. and Gandek, B. (1998) Psychometric and clinical tests of validity of Japanease SF-36 Health Survey. Journal of Clinical Epidemiology, 51, 1045-1053. doi:10.1016/S0895-4356(98)00096-1

[31] Fukuhara, S., Bito, S., Green, J., Hsiao, A. and Kurokawa, K. (1998) Translation, adaptation, and validation of the SF-36 Health Survey for use in Japan. Journal of Clinical Epidemiology, 51, 1037-1044. doi:10.1016/S0895-4356(98)00095-X

[32] Fukuhara, S. and Suzukamo, Y. (2004) Manual of SF36 ver2 Japanese version. Institute for Health Outcomes \& Process Evaluation Research, Kyoto.

[33] Yoshimura, K., Oka, Y., Kamoto, T., Tsukamoto, T., Oshiro, K., Suzukamo, Y., Kinukawa, N. and Ogawa, O. (2009) Night-time frequency, sleep disturbance and general health-related quality of life: Is there a relation? International Journal of Urology, 16, 96-100.

[34] Fukuhara, S. and Suzukamo, Y. (2004) Manual of SF36 ver2 Japanese version. Institute for Health Outcomes \& Process Evaluation Research, Kyoto.

[35] Takemura, T., Kanbayashi, H., Inoue, Y., Uchimura, N., Ito, H., Takemura, T. and Shimizu, T. (2007) Improvement of the QOL by the insomniac treatment in the daytime,-Day- QOL-study. Treatment, 89, 2376-2380.

[36] Ministry of Internal Affairs and Communications (2012) national survey of social life in Japan, 2004. http://www.stat.go.jp/data/shakai/2006/index.htm

[37] Suzuki, S., Takaki, H., Yasumura, Y., Sakuragi, S., Takagi, S., Tsutsumi, Y., Aihara, N., Sakamaki, F. and Goto, Y. (2005) Assessment of quality of life with 5 different scales in patients participating in comprehensive cardiac rehabilitation after acute myocardial infarction. Circulation Journal, 69, 1527-1534. doi:10.1253/circj.69.1527

[38] Yasuhara, Y., Takada, S., Tanioka, T. and Locsin, R.C. (2010) Illness experiences of patients with ischemic heart disease during their transitional phase from hospitalization to discharge in Japan. The Journal of Medical Investigation, 57, 293-304. doi:10.2152/jmi.57.293 